\title{
Confirmatory factor analysis of the Multi-dimensional Emotional Empathy Scale in the South African context
}

\author{
Authors: \\ Chantal Olckers ${ }^{1}$ \\ Michiel A. Buys ${ }^{1}$ \\ Stephanie Grobler ${ }^{1}$
}

\section{Affiliations:}

${ }^{1}$ Department of Human Resource Management,

University of Pretoria,

South Africa

\section{Correspondence to:}

Chantal Olckers

email:

chantal.olckers@up.ac.za

\section{Postal address:}

Room 3-95, EMS Building,

Department of Human

Resource Management,

Faculty of Economic and

Management Sciences,

University of Pretoria,

Lynnwood Road, Pretoria

0001, South Africa

Keywords:

confirmatory factor analysis; construct validity; empathy; emotional intelligence (EQ)

\section{Dates:}

Received: 02 Sept. 2009

Accepted: 28 July 2010

Published: 05 Nov. 2010

How to cite this article: Olckers, C., Buys, M.A., \& Grobler, S. (2010).

Confirmatory factor analysis of the Multi-

dimensional Emotional

Empathy Scale in the South

African context. SA Journal of Industrial Psychology/SA Tydskrif vir Bedryfsielkunde, 36(1), Art. \#856, 8 pages.

DOI: 10.4102/sajip v36i1.856

This article is available at: http://www.sajip.co.za

(C) 2010. The Authors. Licensee: OpenJournals Publishing. This work is licensed under the Creative Commons Attribution License.

\section{ABSTRACT}

Orientation: Empathy is a core competency in aiding individuals to address the challenges of social living. An indicator of emotional intelligence, it is useful in a globalising and cosmopolitan world. Moreover, managing staff, stakeholders and conflict in many social settings relies on communicative skills, of which empathy forms a large part. Empathy plays a pivotal role in negotiating, persuading and influencing behaviour. The skill of being able to empathise thus enables the possessor to attune to the needs of clients and employees and provides opportunities to become responsive to these needs.

Research purpose: This study attempted to determine the construct validity of the Multi-dimensional Emotional Empathy Scale within the South African context.

Motivation for the study: In South Africa, a large number of psychometrical instruments have been adopted directly from abroad. Studies determining the construct validity of several of these imported instruments, however, have shown that these instruments are not suited for use in the South African context.

Research design, approach and method: The study was based on a quantitative research method with a survey design. A convenience sample of 212 respondents completed the Multi-dimensional Emotional Empathy Scale. The constructs explored were Suffering, Positive Sharing, Responsive Crying, Emotional Attention, a Feel for Others and Emotional Contagion. The statistical procedure used was a confirmatory factor analysis.

Main findings: The study showed that, from a South African perspective, the Multi-dimensional Emotional Empathy Scale lacks sufficient construct validity.

Practical/managerial implications: Further refinement of the model would provide valuable information that would aid people to be more appreciative of individual contributions, to meet client needs and to understand the motivations of others.

Contribution/value-add: From a South African perspective, the findings of this study are significant in that the data indicate potential for measuring emotional empathy in the workplace. Research into emotional empathy in South Africa, however, is limited and additional studies could deepen the case for the Scale's applicability and validity.

\section{INTRODUCTION}

\section{Background}

Effective communication is essential for achieving optimum collaboration in an organisation. To improve effective communication, detailed awareness of one's internal world as well as of the external environment is required. People who excel in communication therefore share a tendency to recognise their own internal worlds. Their attitudes, behaviours and sensations are easily apprehended, their emotional states are identifiable and they attract appropriate responses. This internal ability allows for comprehension of the external world and enables such people to identify and correctly evaluate emotional states in others (Cuceloglu, 1994). Mutual comprehension contributes to the development of confidence-based relationships. This mutuality in relations requires the possession of empathetic skills (Toremen, Ekinci \& Karakus, 2006).

According to Hardwick (2007), emotions are rarely verbalised and it is non-verbal cues that form the bulk of human expression. To a large extent, the ability to read these non-verbal cues enables accurate intuition of the feelings that others may be experiencing. This ability to sense what others feel on the basis of tacit communication creates the requisite interpersonal sensitivity required to demonstrate empathy. The essence of highly developed empathy is distilled into the ability to listen to the whole person and correctly understand the person's feelings and circumstances (Covey, 1992).

Empathy is a core competency that assists people in addressing the challenges of social living. The increased integration of personnel into the modern marketplace puts a premium on teamwork. Empathy, in a teamwork context, allows people to understand one another's views, to motivate one another, to assist one another in alleviating the stress that individual team members may experience and to move across culturally defined barriers (Goleman, 1998). Furthermore, cultural sensitivity is increasingly important in a multicultural society, such as that in South Africa. The presence of empathy exists in the presence of emotional intelligence (EQ), which aids cross-cultural interactions.

\section{Defining empathy}

The concept of empathy gained currency in the late 19th century in German aesthetic and psychological 
circles. According to Montag, Gallinat and Heinz (2008), Lipps coined the German word Einfühlung to describe the unity of the object with the observing self. This object-subject sense of unity enables the self to acquire knowledge through the process of inserting the self into 'other view' mode. This other-view mode enables a person to experience the world from inside the worldviews of others without necessarily absorbing their values (Dokmen, 2002; Gulseren, 2001). Titchner later started to use the word 'empathy'. He derived this from the Greek empatheia, em meaning 'within' or 'inside' and pathia meaning 'perception' or 'perspective'. The creation of this direct referent has aided the progress and constant study of conceptions of the content of empathy (Dokmen, 2002; Gulseren, 2001).

According to Stein and Brook (2000), empathy is the ability to be aware of, to understand and to appreciate the feelings and thoughts of others and to be sensitive to what, how and why people feel and think the way that they do. They added that empathetic people care about others and show an interest in and concern for them. Stein and Brook also contended that three main misconceptions about empathy may prove to be obstacles in individual minds. These misconceptions inhibit people from turning empathetic characteristics to their personal advantage. The first misconception conflates empathy with being polite and making pleasant and polite statements. Secondly, empathy may be misconstrued as a demonstration of sympathy. Empathy and sympathy, however, are two distinct emotions and are separate concepts; for example, sympathetic statements are first-person driven but empathetic statements begin with the second-person reference point as the initiator to the statements. Thirdly, some people believe that empathetic consociation necessarily means an endorsement of an opposing viewpoint. Stein and Brook, however, suggested that empathy does not amount to an uncritical adoption of the views that other people may hold; it merely acknowledges the validity of the perspective (or perspectives) of others without passing a value judgment on the statement content of the speakers.

In his definition of empathy, Rogers (1980) suggested that the art of empathy entails the willing process of inserting one's self into the same perspective space that another person occupies. This otherness perspective allows one to intuit the feelings and thoughts of another person and to convey this awareness to the person (Dokmen, 2002; Eisenberg \& Delaney, 1998).

A lack of empathy in relationships may cause conflict and reduce the value or effectiveness of communicative interfaces. A lack of emotional unity reduces communication to isolated sensations but the presence of empathy facilitates the insertion of meaning into communication (Baltas \& Baltas, 2000; Goleman, 1998).

\section{Emotional intelligence and empathy}

Hardwick (2007) linked empathy to emotional intellegence (EQ), noting that several studies have shown that emotional attunement - or empathy - has little to do with rational intelligence.

Goleman (1998) stated that empathy comprises the essential element of EQ, a fundamental element of social awareness. He contended that EQ significantly contributes to the success of individuals in life. His definition of empathy covers the ability to comprehend the feelings of others, extending to the intelligent usage of these comprehension skills to developing stronger interpersonal relationships and competent decision-making skills. Professions in which frequent interactions between people occur undoubtedly require sharpened empathic skills. As such, the future prospects of individuals depend on how they manage these interactions.

According to Goleman (1998), empathy is an internalised process. Tacitly sensing what others feel is what comprises the essence of empathy. Words seldom convey what people feel. The discernment of people's feelings through non-verbal cues and subtle communications relies on self-awareness and self-control. The inability to discern one's own emotional states therefore inhibits the perception of such in other people. Empathy acts as a form of social radar, the absence of which leads to social ineptitude. If we are incapable of discerning the emotional states of others, we may misconstrue emotional states for something that they are not and we may become indifferent, insensitive, even provoke hostility. These failings inhibit the formation of rapport and lead to the stereotyping of others without their being engaged as unique individuals.

Conversely, empathy requires the ability to read emotions at a higher level, the level of tacit communication in which the unspoken becomes more important than what is verbalised (Goleman, 1998). At the highest level, empathy is the ability to discern motivations and issues that inspire feelings in others. We can divine and interpret such causalities only if we put our own emotional states into temporary suspension; this allows us to be open to the feelings of others (ibid.).

Self-awareness is a prerequisite to the exercise of empathy. Goleman (1998) suggested that we should be able to recognise our own responses and sensations emerging from within our own consciousnesses and emotional states. Self-discernment in these areas determines the degree of empathic efficacy and is the core component of any profession requiring empathetic ability. As a rough guide, empathy forms the cornerstone of the social competencies required in people-orientated professions. The supports of empathy are built on leadership and peoplemanagement skills, which are listed as follows:

- People who understand others have a genuine regard for their concerns and display a sincere interest in them.

- People who are in service-orientated posts and are empathic can recognise and anticipate the needs of customers.

- People who are empathic can sense the developmental needs of others and aid them to cultivate their abilities.

- People who respect and relate to others from varied backgrounds are sensitive to group differences and can exert a networking influence that cuts across cultural and ethnic cleavages.

- People with political awareness can read and act upon the power dynamics of an organisation.

EQ requires the ability to identify and apportion the correct significance to one's own feelings and those of other individuals. This ability enables one to deal effectively with people. Such efficacy reduces anxiety, nervousness, hostility and anger. Effective people skills enable a higher degree of collaborative problem-solving, enhance life-work balance and produce the kind of enthusiasm that unleashes creativity.

\section{The role of empathy}

Empathy is a powerful interpersonal tool that is frequently underutilised (Martinuzzi, 2006). A perception exists that empathic people are pathetic, are overly polite and lack an edgy or dynamic personality (Duan \& Hill, 1996). This view needs to be challenged. For us to improve our relationships, we require the ability to see things from the perspective of others. Our reasoning capacities, when brought to bear on understanding others, their motivations, their thoughts and their emotional states and concerns, aid us in understanding issues and perspectival approaches. The ability to care or to show concern does not require us to offer perpetual unconditional agreement with the person agitating our sensibilities. It requires merely that we tune into their frequency to understand their concerns better. The role of empathy in effective leadership and effective anger and change management, in customer service and in deepening intergroup relationships is discussed briefly below.

There is a growing body of literature devoted to the study of empathy as a tributary leadership skill. Empathy underlies relationship-orientated behaviours. These behaviours are hallmarked by consideration, mutual trust and respect and support for the feelings of others (Judge, Piccolo \& Ilies, 2004). A high degree of consideration connotes a highly developed sensitivity to the needs of others, particularly of followers. 
Empathy is but one dimension of EQ. Overall, a successful leader demonstrates the ability to employ the discernments of emotional states occurring in other individuals (Wong \& Law, 2002).

Anecdotal evidence includes empathy in the primary value sets with which leaders are attributed. Other core leadership competencies include the ability to lead with competence and integrity and to direct the efforts of others by demonstrating to them that their values and visions are coterminous with those of the leaders. Leaders transcend their self-interests only through the application of empathy. Their ability to listen and to understand the views, fears and motivations of others clarifies the action that the group should take. Leaders are attributed with an ability to personalise their relations with others, which explains why the personal touch creates the impression of concern. This impression is created specifically through the infusion of optimism in followers and the additional sense that leaders are a resource to all (Autry, 2001; Kouzes \& Posner, 1993).

The ability to understand the emotional states of others and to behave contextually and appropriately aids in managing their emotional states (Humphrey, 2002). One has to demonstrate positive emotions, such as hope, empathy, caring, consideration and understanding (Goleman, 1998; Humphrey, 2002; Salovey \& Mayer, 1990). Cognition and emotion are intertwined and the importance that one attaches to issues determines one's emotional responses. Leaders who exhibit the capacity to control their emotions may be more notably capable of creating positive relations with others based on trust and empathy (Humphrey, 2002).

Acuity in interpreting people allows us to cultivate bonds of trust with others, giving us insight into their internal perspectives. It aids us in understanding their motivations and to adapt to change and manage anger responses. We can manage these necessities and responses by suspending our value judgments and attempting to understand what is said or done. This is a viable approach, providing that our aim is to understand and not to judge. In this, understanding people through our relationships with them is integral to ordering our interactions with them.

From the perspective of the managerial sciences, managers profit from the development and deployment of empathetic skills. Firstly, the application of empathy enables managers to anticipate possible resistance better and to devise methods of how best to handle such resistance. Secondly, as a supportive tool, empathy aids in creating a sense of feeling valued in times of organisational and environmental instability. Thirdly, the ability to understand people enables managers to determine the motivations that they have for acting and to employ these motivations to support the activities and objectives of the whole. Fourthly, loyalty and commitment emerge from the formation of network relationships (Salovey \& Mayer, 1990).

The motive to exercise empathy is to improve human relations. Demonstrating empathy requires a developed ability to listen attentively, developing understanding through the use of probing questions and withholding judgment of an individual's fears and concerns. This ability aids one in managing change and reducing the friction accompanying change. Resistance is overcome through morale-elevating interactions, which contribute to the development of organisational commitment. Depending on the focus of commitment, change can be sustained if loyalty to the manager, the firm or the process of change is maintained (Bacal, 2006).

The basis of communication, within retail enterprises in particular, may be identified with empathy (Berry, Zeithalm \& Parasuraman, 1990; Parasuraman et al., 1988; Redmond, 1989). It provides one with a sensibility that allows one to understand others to the degree where one may predict their social responses. Understanding and predicting demonstrate the presence of empathy and hold the potential of one being the catalyst for improving relations between management and employees and between employees and customers.

We can use empathy as a social coping technique to improve intergroup relations through various means. We can mediate its effects through a number of processes, harnessing the positive effects to produce more balanced attitudes and behaviours (Stephan \& Finlay, 1999). Empathy can also, however, generate poor consequences, which is why it is essential for us to be aware of how we use our psychological cognitive-emotional tools (Triandes, 1972). If we are aware of the failings of empathy, we can maximise the benefits, which include enhancing the effects of intergroup programmes dedicated to facilitating mutual comprehensibility.

\section{Goleman (1998) stated that the}

rules for work are changing. We are now being judged not just by how smart we are or by our training and expertise, but also how well we handle ourselves and each other.

(Goleman, 1998, p. 1)

The ability to discern emotional cues is an important work-life skill, as many people are adept at concealing their authentic emotional orientations (Goleman, 1998).

\section{Measuring empathy}

In recent years, a number of instruments have been introduced to measure empathy. Hogan (1969) developed the Hogan Empathy Scale, Mehrabian and Epstein (1972) developed the Emotional Empathic Tendency Scale, Davis (1980) developed the Interpersonal Relativity Scale Index and Caruso and Mayer (1998) developed the Multi-dimensional Emotional Empathy Scale.

In South Africa, legislation strictly controls the classification, possession, control and use of psychological tests and other instruments relating to work-related individual assessments (Mauer, 2000). The Employment Equity Act No. 55 of 1998 (section 8), Government Gazette (1998), stipulates that only scientifically validated tools may be used to test or assess individuals and that these must be fair and applicable to all individuals. The presence of undue prejudice or bias in any measurement tool disqualifies its use. Stringent employmentequity legislation therefore prohibits the unfair assessment, ranking, classification or profiling of any individual.

The above legislation creates a gap for the development of psychological testing instruments that are applicable across cultural boundaries. It seems that the need for instruments that meet the requirements of employment-equity legislation cannot be separated from the needs that arise from the diverse South African social context. When they construct psychological evaluation instruments, psychologists should therefore always bear in mind the social and cultural diversity present in both the historical and the contemporary contexts of the socioeconomic and political environments particular to South Africa (Claassen, 1997).

Despite the need for culturally specific empathy testing instruments, South Africa has generally tended to adopt instruments directly from abroad (Foxcroft, 1997). These instruments have largely been in English and even the adaptations of these instruments still tend to ignore the fundamental cultural differences in South Africa. Studies determining the construct validity of various imported instruments (such as Litwin's and Stringer's organisational climate questionnaire [Olckers, Buys \& Zeeman, 2007], the socialisation questionnaire developed by Chao, O'Leary-Kelley, Wolf, Klein and Gardner [Madurai, Olckers \& Buys, 2008], the revised job diagnostic survey of Hackman and Oldham [Buys, Olckers \& Schaap, 2007]) have shown that they are not suited for use in the South African context. 
The objective of the current study is to determine the construct validity of the Multi-dimensional Emotional Empathy Scale of Caruso and Mayer (1998) within the South African context.

\section{RESEARCH DESIGN}

\section{Research approach}

Empirical data were collected and analysed through a quantitative research approach. This approach was selected because the study was concerned with testing the validity and discerning the appropriateness of the constructed evaluatory model.

\section{Research method}

Survey research was deemed the most appropriate method of measuring the quantitative data (Neuman, 2003). Leedy and Ormrod (2005) defined survey research as research involving the gathering of information about certain characteristics of individuals or groups and analysing their responses to a set of predetermined questions.

\section{Sample}

A convenience sample comprising 212 respondents completed the Multi-dimensional Emotional Empathy Scale.

Table 1 reflects the biographical information of the respondents. The sample of the 212 respondents consisted of 97 Black $(N=97)$ and 115 White $(N=115)$ respondents. In gender-disaggregated terms, $32 \%$ of the respondents were male and $68 \%$ were female. In terms of age, respondents falling in the $21-30$ age category comprised $41 \%$ of the total sample, respondents falling in the $31-40$ age category comprised $27 \%$ respondents falling in the $41-50$ age category comprised $15 \%$. The remaining $2 \%$ fell into the 60-61 year age category. The breakdown of the educational levels and post-secondary qualifications of the respondents was as follows:

- secondary-school certificate $-27 \%$

- post-secondary school diploma $-33 \%$

TABLE 1

Biographical information on the respondents

\begin{tabular}{|c|c|c|c|c|c|}
\hline & & \multirow[b]{2}{*}{ Frequency } & \multirow[b]{2}{*}{$\%$} & \multicolumn{2}{|c|}{$\%$} \\
\hline & & & & Valid & Cumulative \\
\hline \multicolumn{6}{|l|}{ Age } \\
\hline \multirow[t]{7}{*}{ Valid } & 18-20yrs & 9 & 4.20 & 4.20 & 4.20 \\
\hline & $21-30 y r s$ & 86 & 40.6 & 40.6 & 44.8 \\
\hline & $31-40 y r s$ & 57 & 26.9 & 26.9 & 71.7 \\
\hline & $41-50 y r s$ & 31 & 14.6 & 14.6 & 86.3 \\
\hline & $51-60 y r s$ & 22 & 10.4 & 10.4 & 96.7 \\
\hline & $61-70 y r s$ & 7 & 3.30 & 3.30 & 100 \\
\hline & Total & 212 & 100 & 100 & - \\
\hline \multicolumn{6}{|l|}{ Sex } \\
\hline \multirow[t]{3}{*}{ Valid } & Male & 68 & 32.1 & 32.1 & 32.1 \\
\hline & Female & 144 & 67.9 & 67.9 & 100 \\
\hline & Total & 212 & 100 & 100 & - \\
\hline \multicolumn{6}{|l|}{ Race } \\
\hline \multirow[t]{3}{*}{ Valid } & White & 115 & 54.2 & 54.2 & 54.2 \\
\hline & Black & 97 & 45.8 & 45.8 & 100 \\
\hline & Total & 212 & 100 & 100 & - \\
\hline \multicolumn{6}{|c|}{ Qualification } \\
\hline \multirow[t]{6}{*}{ Valid } & Lower than matric & 13 & 6.10 & 6.10 & 6.10 \\
\hline & Matric & 58 & 27.4 & 27.4 & 33.5 \\
\hline & Diploma/Certificate & 69 & 32.5 & 32.5 & 66.0 \\
\hline & Degree & 49 & 23.1 & 23.1 & 89.2 \\
\hline & Post graduate & 23 & 10.8 & 10.8 & 100 \\
\hline & Total & 212 & 100 & 100 & - \\
\hline
\end{tabular}

- university degree - $23 \%$

- post-graduate qualification - $11 \%$.

\section{Measuring instrument}

The measuring instrument used was the Multi-dimensional Emotional Empathy Scale developed by Caruso and Mayer (1998). The instrument consists of 26 items that tap into six areas indicative of emotional empathy, namely Suffering, Positive Sharing, Responsive Crying, Emotional Attention, Emotional Contagion and the degree to which individuals express emotional connectivity to the experiences of others.

A 5-point Likert response scale was used, where 1 was 'strongly disagree' and 5 was 'strongly agree'. An attempt was made to include both positive and negative emotional-response situations. Six negatively worded items were included in the scale to reduce response bias. Caruso and Mayer (1998) reported a reliability coefficient of 0.86 . Individual subscale alpha scores ranged from 0.44 for a two-item subscale to 0.80 for an eightitem subscale.

Table 2 illustrates the items per factor indicator (Caruso \& Mayer, 1998)

\section{Research procedure}

A combination of non-probability sampling techniques was used to obtain the data for the study. Firstly, the researcher used convenient sampling, where the participants who were easiest to obtain were selected to partake in the study. Secondly, the researcher used snowball sampling, where the participants were asked to identify other relevant members from the population who could partake in the study (Welman Kruger \& Mitchell, 2005). This method was repeated until a representative sample had completed the questionnaire. A copy of the questionnaire and letter of informed consent was handed to each respondent for completion and signing, respectively. Participation in the survey was purely voluntary. All data were dealt with in a confidential manner.

\section{Statistical analysis}

Descriptive statistics in respect of the Multi-dimensional Emotional Empathy Scale were computed. These statistics included a descriptive analysis of the biographical data as well as of the content items of the instrument. The reliability of the instrument was also determined. In this study, the most common form of internal consistency reliability, Cronbach's alpha, was used to ascertain the reliability of the elements comprising the six constructs, as recommended by Gregory (2004). Reliability should be 0.70 or higher to indicate adequate convergence or internal consistency (Hair, Black, Babin, Anderson \& Tatham, 2006). To improve the reliability coefficients of the analysis and to prevent the cancelling out of variables with positive and negative loadings, a reversal of the original negative items therefore had to be done in this study. The Statistical Package for the Social Sciences for Windows program was used to do this analysis.

TABLE 2

Items per factor for the Multi-dimensional Emotional Empathy Scale

\begin{tabular}{lccccc}
\hline Suffering & $\begin{array}{c}\text { Positive } \\
\text { Sharing } \\
\text { (5 items) }\end{array}$ & $\begin{array}{c}\text { Responsive } \\
\text { Crying } \\
\text { (3 } \mathbf{3} \text { items) }\end{array}$ & $\begin{array}{c}\text { Emotional } \\
\text { Attention } \\
\text { (4 } \mathbf{4} \text { items) }\end{array}$ & $\begin{array}{c}\text { Feel for } \\
\text { Others } \\
\text { (4 } \text { items) }\end{array}$ & $\begin{array}{c}\text { Emotional } \\
\text { Contagion } \\
\text { (2 items) }\end{array}$ \\
\hline \multicolumn{6}{c}{ Variables } \\
\hline 5 & 14 & 1 & 4 & 10 & 11 \\
6 & 22 & 20 & 9 & 15 & 17 \\
8 & 23 & 25 & 13 & 16 & - \\
12 & 29 & - & 27 & 21 & - \\
18 & 30 & - & - & - & - \\
24 & - & - & - & - & - \\
28 & - & - & - & - & - \\
\hline
\end{tabular}


The data were then analysed by means of confirmatory factor analysis (CFA). In the confirmatory approach, a model based on theory and empirical evidence from previous research is postulated. The model is then tested with a series of fit indexes to determine whether the pattern of variances and covariances in the data is consistent with the postulated theoretical model (Garson, 2005). Structural equation modelling was used in this study to conduct CFA because it focuses on validating the measurement model by obtaining estimates of the parameters of the model and by assessing whether the model itself provides a good fit to the data (Garson, 2005).

The first step of the research process was to define the theoretical factor model. This involved selecting the number of factors to be used and defining the nature of the loadings between the factors and the variables. The six factors, namely Suffering, Positive Sharing, Responsive Crying, Emotional Attention, a Feel for Others and Emotional Contagion, were specified as each being measured by a specific subset of variables.

Maximum likelihood estimation (MLE) was used to estimate the coefficients. According to Garson (2005), MLE is by far the most common model-fitting procedure used, as it picks estimates that have the greatest chance of reproducing the observed data and does not depend on the scale of measurement. A limitation of MLE, however, is that it is sensitive to deviations from normality.

The second step was to evaluate model adequacy by means of goodness-of-fit measures. The following indexes were used in this study:

- chi-square statistics

- the root mean square error of approximation (RMSEA Steiger \& Lind, 1980)

- the goodness of fit index (GFI Jöreskog \& Sörbom, 1989)

- the normed fit index (NFI Bentler \& Bonnet, 1980)

- the comparative fit index (CFI; Bentler, 1990).

With the chi square, the difference between the observed data and the hypothesised model is tested (Garson, 2005). A non-significant chi square indicates that the model shows a good fit with the data and that the difference between the original covariance matrix and the covariance matrix that is reconstructed on the basis of the postulated model is significantly small (Garson, 2005). According to Browne and Cudeck (1993), however, the chi square is often too strict a test, as it is unreasonable to expect that any reconstructed covariance matrix will display perfect fit with the original covariance matrix. Another limitation of the chi-square test is that it is influenced to a great extent by the size of the sample (Hox \& Bechger, 1998).

The RMSEA is influenced by the sample size to a lesser extent. It also takes into consideration the complexity of a postulated model and generally gives preference to simpler models that make use of fewer parameters to explain the covariances between the variables (Garson, 2005). The general guideline for the RMSEA is that values of 0.05 and smaller indicate a close fit between the theoretical model and the observed data. Values of 0.08 and smaller indicate a reasonable fit and values greater than 0.08 or equal to 1 indicate an unsatisfactory fit (Browne \& Cudeck, 1993). One of the strongest points of the RMSEA is that the confidence intervals can be constructed around the point estimations.

A general guideline for the interpretation of the GFI, NFI and CFI is that values of 0.95 and higher indicate a satisfactory fit between the postulated theoretical model and the observed data (Hair et al., 2006)

CFA allows the researcher to estimate the factor pattern coefficients that link the observed variables and the latent variables (Garson, 2005). The correlations between the latent variables can also be estimated. All analyses in this study were carried out with the EQS 6.1 structural equation program.

\section{RESULTS}

The descriptive statistics for the Multi-dimensional Emotional Empathy Scale are reported in Table 3. The variability of the mean, standard deviation, skewness and kurtosis reflects how the participants responded to the different items of the questionnaire. The data that were collected and analysed displayed small but noticeable deviations from the normal distribution

\section{Overall fit}

CFA was used to test the extent to which the six-factor measurement model for the Multi-dimensional Emotional Empathy Scale fitted the data set. The results of Mardia's coefficient test for the presence of multi-variance were significant enough to indicate a violation of the normality assumption underpinning the multivariate analyses. The distribution-free robust maximum probability (ML) consequently suggested that Satorra-Bentler-scaled chi-square statistics should be employed, as recommended by Tabachnick and Fidell (2001).

In terms of the model's chi-square statistics, an insignificant chi square indicated that the model showed a good fit with the data and that the difference between the original covariance matrix and the reconstructed covariance matrix generated from the model's application was significantly small. One of the limitations of the model chi-square fit index is that it is unlikely that an insignificant chi square will be obtained in a large sample, even when the model fits the empirical data well (Kraft, Engelbrecht \& Theron, 2004). The relative chi square, also called the practical chi-square fit index, however, corrects this overstatement (Kelloway, 1998). This fit index correlates directly with the chi-square value and is based on the chi square to the degrees of freedom $\left(\chi^{2} / d f\right)$ (Tabachnick \& Fidell, 2001).

Table 4 depicts the goodness-of-fit information for the robust ML model. The result of the Satorra-Bentler-scaled chi-square statistical-calculation output was 504.7512, with 284 degrees of freedom ( $p=0.000)$ for the sample. This $p$-value is significant with the use of a Type I error rate of 0.05 . This result demonstrates

TABLE 3

Descriptive statistics for the Multi-dimensional Emotional Empathy Scale

\begin{tabular}{|c|c|c|c|c|c|c|c|}
\hline & \multicolumn{3}{|c|}{ Statistic } & \multicolumn{2}{|c|}{ Skewness } & \multicolumn{2}{|c|}{ Kurtosis } \\
\hline & $N$ & Mean & $S D$ & Statistic & $S E$ & Statistic & $S E$ \\
\hline Suffering & 212 & 4.409 & 0.484 & -0.650 & 0.167 & -0.283 & 0.333 \\
\hline Positive Sharing & 212 & 4.313 & 0.575 & -0.423 & 0.167 & -0.821 & 0.333 \\
\hline Responsive Crying & 212 & 3.377 & 1.024 & -0.204 & 0.167 & -0.682 & 0.333 \\
\hline Emotional Attention & 212 & 3.466 & 0.867 & -0.420 & 0.167 & -0.225 & 0.333 \\
\hline Feel for Others & 212 & 3.254 & 0.814 & -0.104 & 0.167 & -0.243 & 0.333 \\
\hline Emotional Contagion & 212 & 3.599 & 0.813 & -0.090 & 0.167 & -0.425 & 0.333 \\
\hline Valid $N$ (listwise) & 212 & - & - & - & - & - & - \\
\hline
\end{tabular}

$N$, number of items; $S D$, standard deviation; $S E$, standard error. 
TABLE 4

Fit indices for the postulated measuring model $(N=212)$

Fit indices

\begin{tabular}{ccccccc}
\hline$\chi^{2}$ & $\chi^{2} / d f$ & $d f$ & GFI & NFI & CFI & RMSEA \\
\hline 504.751 & 0.096 & 284 & 0.838 & 0.745 & 0.86 & 0.061 \\
\hline
\end{tabular}

$90 \%$ Confidence interval of RMSEA $=(0.052 ; 0.069) ; \mathrm{GFI}$, goodness of fit index; NFI, normed fit index; $\mathrm{CFI}$, comparative fit index; RMSEA, the root mean square error of approximation

a poor overall fit of the six factors originally measured on the EQS. Given the sample size and chi-square/df ratio, however, it would be hasty to accept a poor model fit based on the significance of the chi square alone (Kelloway, 1998). Carmines and McIver (1981), for example, claimed that relative chi square reaches acceptable modular tolerance in a range of 2:1 to 3:1. Ullman (2001) claimed that two or less reflects a good fit. Kline (1998) maintained that three or less is acceptable. The $\chi^{2} / d f$ ratio of 1:78 can therefore be interpreted as indicating an acceptable fit. Given the problems associated with using this test alone, however, other fit statistics needed to be examined.

The RMSEA had a value of 0.061 , with a $90 \%$ confidence interval in the 0.052 to 0.069 range. Considering the general guideline by Browne and Cudeck (1993), values of 0.05 and less indicate a tight correlation between the postulated model and the empirical data. Values greater than 0.08 indicate a poor fit, while values at or below 0.08 indicate acceptable tolerance. This indicates that the RMSEA value deems the model a reasonable fit.

As indicated in Table 4, the values of the GFI, NFI and CFI were $0.838,0.745$ and 0.860 respectively. A value of 0.95 is considered to be a good fit for all the above indexes (Hair et al., 2006). None of the values, however, met the guideline of acceptable tolerance.

The structural equation model for the six factors underlying the empathy scale is given in Figure 1. Latent variables were permitted to correlate with one another, as is depicted by the curve arrows between them. Path coefficients (factor loadings) show high correlations between some of the constructs, namely Suffering and Positive Sharing (0.807), Suffering and Feel for Others (0.719) and Feel for Others and Emotional Contagion (0.754). The observable variables load on one factor alone. The arrows consequently depict path coefficients from these observed variables to only one corresponding latent variable Path coefficients for Suffering, factor 1, vary between 0.46 and 0.72. For Positive Sharing, factor 2, the coefficients vary from 0.70 to 0.77 . Responsive Sharing, factor 3 , results range from 0.51 to 0.81 . Coefficients for Emotional Attention, factor 4, range in the 0.22 to 0.69 band. Feel for Others, factor 5 , ranges in the 0.35 to 0.64 band. Emotional Contagion, factor 6, ranges from 0.30 to 0.64 . Certain variables yield low coefficients: variable $9(0.22)$, variable $16(0.35)$ and variable $11(0.30)$ demonstrate these low yields.

\section{Reliability}

Alpha coefficients for the subscale ranged from 0.316 to 0.852 , with 0.791 (Suffering), 0.852 (Positive Sharing), 0.686 (Responsive Crying), 0.508 (Emotional Attention), 0.607 (emotive connection with others, which was labelled Feel for Others) and 0.316 (Emotional Contagion). Emotional Contagion appeared to have the least acceptable coefficient. Nunnaly (1978) suggested that a 0.70 rating is an acceptable coefficient. Morgan and Griego (1998) and Santos (1999) suggested that lower thresholds appear in modelling because of a lack of the homogeneity of variances among items and because of the presence of fewer items in the scale and/or factor

\section{DISCUSSION}

Empathy is a core ingredient of teamwork, communication, leadership, globalisation and cross-cultural sensitivity. No standard, applicable instrument, however, has thus far been

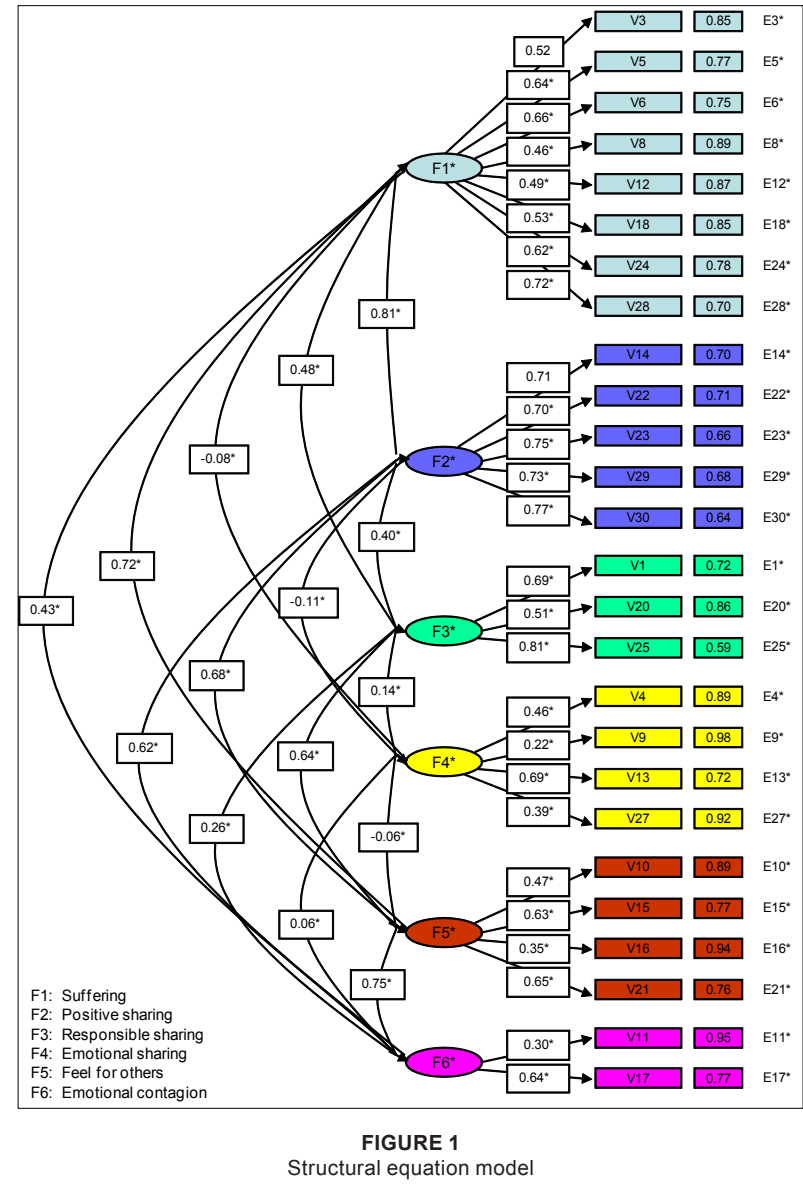

found to cater for the measurement of empathy particular to the multicultural South African social experience. The research presented here is therefore specifically concerned with establishing the construct validity of the Multi-dimensional Emotional Empathy Scale.

Validity can be established only when based on evidence that the model accurately measures what it claims to measure. The logic of items comprising the social concepts tested here is what determines construct validity, as Garson (2005) suggested. To determine whether or not the identified scales correlate, factor analysis must answer the construct validity question. It was therefore necessary to verify the appropriateness of the scores yielded in this test, as suggested by Stapleton (1997).

CFA was used to perform this functional assessment of the Multi-dimensional Emotional Empathy Scale. The relationships between the items or observed variables comprising the six constructs of emotional empathy were therefore tested by means of CFA. This deepened insight into the factor structure of the Multi-dimensional Emotional Empathy Scale. The significance of this study's findings, however, does not demonstrate sufficient construct validity of the Multidimensional Emotional Empathy Scale.

The individual factor loadings were assessed in respect of the criteria for construct validity. Standardised loading estimates should be 0.50 or higher; ideally they should be 0.70 or higher (Garson, 2005; Hair et al., 2006). According to this criterion, the following variables demonstrate low yields: variable $9(0.22)$ and variable 27 (0.39) link to Emotional Attention; variable 16 (0.35) links to Feel for Others and variable $11(0.30)$ links to Emotional Contagion. Low loadings suggest that a variable is a candidate for deletion from the model.

As indicated by the results of the reliability analysis, total scale reliability has an acceptable tolerance of 0.848 . The alpha 
TABLE 5

Item analysis for the sub-scales

\begin{tabular}{lll}
\hline Suffering & $\begin{array}{l}\text { Corrected item-total } \\
\text { correlation }\end{array}$ & $\begin{array}{l}\text { Cronbach's alpha if } \\
\text { the item is deleted }\end{array}$ \\
\hline Item 3 & 0.460 & 0.790 \\
Item 5 & 0.531 & 0.764 \\
Item 6 & 0.656 & 0.743 \\
Item 8 & 0.427 & 0.779 \\
Item 12 & 0.439 & 0.777 \\
Item 24 & 0.551 & 0.760 \\
Item 28 & 0.594 & 0.753 \\
Item 18 & 0.438 & 0.779 \\
Scale reliability 0.791 & &
\end{tabular}

Positive Sharing

$\begin{array}{lll}\text { Item } 14 & 0.650 & 0.824 \\ \text { Item 22 } & 0.655 & 0.823 \\ \text { Item 23 } & 0.691 & 0.814 \\ \text { Item 29 } & 0.617 & 0.833 \\ \text { Item } 30 & 0.702 & 0.810\end{array}$

Scale reliability 0.852

Responsive Crying

Item 1

Item 20

Item 25

0.510

0.407

0.589

0.722

Scale reliability 0.686

Emotional Attention

Item 4

Item 9

Item 13

Item 27

0.603

0.451

Scale reliability 0.508

\section{Feel for Others}

Item 10

Item 15

Item 16

0.345

0.202

0.329

0.330

0.518

0.408

0.409

Item 21

0.379

0.546

0.454

0.593

Scale reliability 0.607

Emotional Contagion

Item 1

\subsection{8}

0.(a)

Item 17

0.188

0.(a)

reliability $\mathbf{0 . 3 1 6}$

The value is negative due to a negative average covariance among items. This violates reliability model assumptions.

coefficients for the subscale ranged from 0.508 to 0.852 , the emotional cognition construct yielding the lowest reliability, at 0.316 . Previous research has indicated that this element demonstrates low-yielding reliability in the 0.44 range (Caruso \& Mayer, 1998). Given that only items 11 and 17 comprised the emotional cognition scale and that their values were negative, these items should therefore be omitted from routine empathy research.

Brown (2000) averred that unreliable instruments cannot be classed as valid. Any unreliable element in the model should therefore be omitted if the overall modular integrity is compromised by the retention of the unstable elements. All the items on the Multi-dimensional Emotional Empathy Scale function effectively, with the exception of item 20, which forms part of the Responsive Crying series and item 9 from the Emotional Attention series. These two items are negatively stated. There should therefore be reasonable concern over their suitability to the South African environment, unless they are revised.

The preliminary evidence that emerged from the current study suggests that the Multi-dimensional Emotional Empathy Scale

may be of some use to employees and managers in South Africa because it does appear to enable assessments of their empathy skills. The significance of this study's findings, however, does not demonstrate sufficient construct validity of the Multidimensional Emotional Empathy Scale and additional studies should therefore be commissioned to deepen the case for the Multi-dimensional Emotional Empathy Scale's applicability and validity. The following limitations and recommendations of the study should moreover be borne in mind in the assessment of this study's findings:

1. The researchers were not physically present when the respondents completed the questionnaire. If any respondents sought clarification on the meaning or intention of a question, none could therefore be supplied, which could have clouded the results due to uncertainty in some respondents.

2. The sample size $(N=212)$ was adequate to test the model but it is recommended that future research be conducted on a larger, more heterogeneous sample.

3. Four to six elements per data series should be regarded as essential to determining the validity of an underlying construct (Idaszak \& Drasgow, 1987). In the Multidimensional Emotional Empathy Scale, Responsive Crying was measured by three items and Emotional Contagion by two.

4. The alpha coefficients for the subscales ranged between 0.361 and 0.852 . This is not sufficient to indicate adequate congruence between the model and the data. Byrne (2001) suggested that reliability can be established by a Cronbach alpha of 0.70 The alpha is reduced through an increasing level of variance heterogeneity among items. It is further reduced when fewer elements are included in each of the generic series under testing. It is recommended that the items for the instrument that yielded low reliability be taken out to determine the influence thereof on the resulting findings of future validation studies.

5. Future validation studies should focus on improving the model fit of the theoretical model underpinning this measure of empathy. It would also be useful to review the theory underpinning this instrument by postulating more than one model and determining its fit to the data observed to obtain a better model fit.

\section{Conclusion}

Empathy aids in developing essential skills, such as communication, persuasion and influencing. When people read the feelings of others correctly, they can reduce the amount of conflict that people experience. Emotional empathy can aid in developing customer and supplier relations and can facilitate general interaction with the public. The personal benefits to staff trained in emotional-empathy modes of behaviour can have marked impacts on productivity and conflict in the workplace.

From a South African perspective, the findings of this study are significant in that the data do not demonstrate sufficient construct validity of the Multi-dimensional Emotional Empathy Scale. Further refinement to the model would provide valuable information that would aid people to be more appreciative of individual contributions, to meet client needs and to understand the motivations of others. Because research into emotional empathy in South Africa has thus far been limited, this field in general and this Scale in particular require deeper exploration.

\section{REFERENCES}

Autry, J. (2001). The Servant Leader. Roseville: Prima Publishing. Bacal, R. (2006). Empathy - Key to change management. Retrieved September 15, 2007, from http://www.work911.com/ managingchange/changekeyempathy.htm

Baltas, A., \& Baltas, Z. (2000). Stress and the ways to cope with it. Istanbul: Remzi Kitabevi. 
Bentler, P.M. (1990). Comparative fit indexes in structural models. Psychological Bulletin, 107, 238-246.

Bentler, P.M., \& Bonnet, D.G. (1980). Significance tests and goodness of fit in the analysis of covariance structures. Psychological Bulletin, 88, 588-606.

Berry, L.L., Zeithaml, V.A., \& Parasuraman, A. (1990). Five imperatives for improving service quality. Sloan Management Review, 31(4), 29-38.

Brown, J.D. (2000). Statistics corner questions and answers about language testing statistics: What is construct validity? Shiken: JALT Testing E Evaluation SIG Newsletter, 4(2), 7-10.

Browne, M.W., \& Cudeck, R. (1993). Alternative ways of assessing model fit. In K.A. Bollen \& J.S. Long (Eds.), Testing structural equation models, (pp. 136-162). Thousand Oaks: Sage.

Buys, M.A., Olckers, C., \& Schaap, P. (2007). The construct validity of the revised job diagnostic survey. South African Journal of Business Management, 38(2), 33-40.

Byrne, B. (2001). Structural equation modeling with Amos. Rahwah: Lawrence Erlbaum.

Carmines, E.G., \& McIver, J.P. (1981). Analysing models with unobserved variables: Analysis of covariance structures. In G.W. Bohmstedt \& E.F. Borgatta (Eds.), Social measurement, (65-115). Thousand Oaks: Sage

Caruso, D.R., \& Mayer, J.D. (1998). A measure of emotional empathy for adolescents and adults. Unpublished manuscript, University of New Hampshire, Durnham.

Claassen, N.C.W. (1997). Culture differences, politics and test bias in South Africa. European Review of Applied Psychology, $47,297-307$.

Covey, S.R. 1992. The seven habits of highly effective people. New York: Simon \& Schuster.

Cuceloglu, D. (1994). The child within us. Istanbul: Remzi Kitabevi.

Davis, M.H. (1980). A multidimensional approach to individual differences in empathy. JSAS Catalogue of Selected Documents in Psychology, 10(85), 1-19

Dokmen, U. (2002). Communicative conflicts and empathy. Istanbul: Sistem Yay.

Duan, C., \& Hill, C.E. (1996). The current state of empathy research. Journal of Counseling Psychology. 43(3), 261-274.

Eisenberg, S., \& Delaney, D.J. (1998). The process of psychological guidance. Istanbul: M.E.B.

Foxcroft, C.D. (1997). Psychological testing in South Africa: Perspectives regarding ethical and fair practices. European Journal of Psychological Assessment, 13, 229-235.

Garson, G.D. (2005). Statsnotes: An online textbook, PA 765 Retrieved September 15, 2007, from http://www. statisticssolutions.com/Validity.htm

Goleman, D. (1998). Working with emotional intelligence. London: Bloomsbury Publishing.

Gregory, R.J. (2004). Psychological testing: History, principles, and applications. (4th edn.). Boston: Pearson.

Gulseren,S. (2001). Empathy: A review on its definition and usage. Turkish Psychiatry Journal, 12(2), 133-145.

Hair, J.F. Jr., Black, W.C., Babin, B.J., Anderson, R.E., \& Tatham, R.L. (2006). Multivariate data analysis. (6th edn.). Upper Saddle River: Pearson Prentice Hall.

Hardwick, M.W. (2007). Audience-centered focus as a critical factor for presentation success. Retrieved September, 15, 2007, from http://www.plusoneperformance.com/resources/audiencecentered.cfm

Hogan, R. (1969). Development of an empathy scale. Journal of Consulting and Clinical Psychology, 33, 307-316.

Hox, J.J., \& Bechger, T.M. (1998). An introduction to structural equation modelling. Family Science Review, 11, 354-373.

Humphrey, R.H. (2002). The many faces of emotional leadership. Leader Quarterly, 13(5), 493-504.

Idaszak, J.R., \& Drasgow, F. (1987). A review of the job diagnostic survey: Elimination of a measurement artefact. Journal of Applied Psychology, 72(1), 69-72.

Jöreskog, K.G., \& Sörbom, D. (1989). LISREL 7: A guide to the program and applications. (2nd edn.). Chicago: SPSS
Judge, T.A., Piccolo, R.F., \& Ilies, R. (2004). The forgotten ones? The validity of consideration and initiating structure in leadership research. Journal of Applied Psychology, 89(1), 36-51.

Kelloway, E.K. (1998). Using LISREL for structural equation modelling: A researcher's guide. Thousand Oaks: Sage.

Kline, R.B. (1998). Principles and practice of structural equation modeling. New York: Guilford.

Kouzes, J.M., \& Posner, B.Z. (1993). Credibility: How leaders gain and lose it, why people demand it. San Francisco: Jossey-Bass.

Kraft, P., Engelbrecht, A.S., \& Theron, C.C. (2004). The influence of transformational and transactional leadership on dyadic trust relationships through perceptions of fairness. South African Journal of Industrial Psychology, 30(1), 10-18.

Leedy, P.D., \& Ormrod, J.E. (2005). Practical research: Planning and design. (8th edn.). Upper Saddle River: Pearson.

Madurai, M., Olckers, C., \& Buys, M.A. (2008). The construct validation of an instrument designed to assess organizational socialisation. South African Journal of Industrial Psychology. 34(1), 1-9.

Martinuzzi, B. (2006). What's empathy got to do with it? Retrieved August 19, 2007, from_http://www.mindtools.com/pages/ article/newLDR_75.htm

Mauer, K.F. (2000). Psychological test use in South Africa. Pretoria: University of South Africa.

Mehrabian, A., \& Epstein, N. (1972). A measure of emotional empathy. Journal of Personality, 40, 525-543.

Montag, C., Gallinat, J., \& Heinz, A. (2008). Theodor Lipps and the concept of empathy: 1851-1914. American Journal of Psychology, 165(10), 1.

Morgan, G.A., \& Griego, O.V. (1998). Easy use and interpretation of SPSS for Windows. Mahwah: Lawrence Erlbaum.

Neuman, W.L. (2003). Social research methods. Boston: Pearson Education.

Nunnaly, J. (1978). Psychometric theory. New York: McGraw-Hill

Olckers, C., Buys, M.A., \& Zeeman, A. (2007). The construct validity of Litwin $\mathcal{E}$ Stringer's organisational climate questionnaire in a South African context. Paper presented at the 13th European Congress of Work and Organisational Psychology, Stockholm.

Redmond, M.V. (1989). The functions of empathy in human relations. Human Relations, 42(7), 593-605.

Rogers, C.R. (1980). A way of being. Boston: Houghton Mifflin.

Salovey, P., \& Mayer, J.D. (1990). Emotional intelligence Imagination, Cognition and Personality, 9, 185-211.

Santos, J.R.A. (1999). Cronbach's alpha: A tool for assessing the reliability scales. Journal of Extension, 37(2). Retrieved September 15, 2007, from http://joe.org/joe/1999april/tt3. html

Stapleton, C.D. (1997). Basic concepts and procedures of confirmatory factor analysis. Retrieved September 1, 2007, from http:// ericae.net/ft/tamu/Cfa.htm

Steiger, J.H., \& Lind, J.C. (1980). Statistically based tests for the number of common factors. Paper presented at the annual meeting of the Psychonomic Society, Iowa City.

Stein, S.J., \& Brook, H.E. (2000). The EQ edge: Emotional intelligence and your success. Toronto: Stoddart.

Stephan, W.G., \& Finlay, A.K. (1999). The role of empathy in improving intergroup relations. Journal of Social Issues, 55(4), 729-743.

Tabachnick, B.G,. \& Fidell, C.S. (2001). Using multivariate statistics. (4th edn.). Boston: Allyn and Bacon.

Toremen, F., Ekinci, A., \& Karakuş, M. (2006). Influence of managers' empathic skills on school success. International Journal of Educational Management, 20(6), 490-499.

Triandis, H.C. (1972). The analysis of subjective culture. New York: John Wiley \& Sons.

Ullman, J.B. (2001). Structural equation modelling. In B.G. Tabachnick \& L.S. Fidel (Eds.), Using multivariate statistics. (4th edn., pp. 653-771). Needham Heights: Allyn \& Bacon.

Welman, C., Kruger, F., \& Mitchell, B. (2005). Research methodology. (3rd edn.). Oxford: Oxford University Press.

Wong, C.S., \& Law, K.S. (2002). The effects of leader and follower emotional intelligence on performance and attitude: An exploratory study. The Leadership Quarterly, 13, 243-274. 